\title{
Neuroprotective Effects of Ginkgo Biloba Extract (GbE) on Oxygen-Glucose Deprivation (OGD) in PC12 Cells
}

\author{
Chunli Mei ${ }^{1}$, Xuelu Han ${ }^{1}$, Jing Zhang ${ }^{1}$, Ling Gao ${ }^{1 *}$, Huimin Liu ${ }^{1,2^{*}}$ \\ ${ }^{1}$ Beihua University, Jilin, 132013, China \\ ${ }^{2}$ Department of Neurology, Affiliated Hospital, Beihua University, Jilin, 132013, China \\ Email: meixiaoqing2007@126.com \\ Received April 2013
}

\begin{abstract}
Ischemic cerebrovascular disease is a global health problem. According to the World Health Organization, ischemic stroke is actually the most common cause of death in the world. Ginkgo biloba extract (GbE) is a traditional Chinese medicine for angina pectoris. Ginkgo biloba plays a role in expanding blood vessels, increasing coronary and cerebral blood flow, preventing platelet aggregation, inhibiting thrombosis, and improving the microcirculation. In the present study, we investigated the mechanisms involved in the neuroprotective effects of $\mathrm{GbE}$ in a model of hypoxic-ischemic brain disease. We used NGF (100 ng/ml for 6 days) and OGD (5\% $\mathrm{CO}_{2}$ and $95 \% \mathrm{~N}_{2}, 1 \mathrm{mmol} / \mathrm{l} \mathrm{NaS}_{2} \mathrm{O}_{4}$ in sugar-free DMEM for $16 \mathrm{~h}$ ) to stimulate PC12 cells and convert them into neurons in order to establish an ischemia model. The results showed that PC12 cells transformed into cells that looked like neurons and that MAP2 was up-regulated in NGF-treated PC12 cells. Cell apoptosis was found to be up-regulated after NGF stimulation and OGD. The apoptosis rate after 16 hours of OGD was $19.44 \%$. GbE (50 ng/ml) reduces apoptosis rate to $11.35 \%$. These results may help to show that NGF treatment can be combined with OGD to establish an in vitro model of acute ischemic brain damage. In the present study, we find that GbE effectively increases the survival rate of PC12 cells and relieves OGD damage. These results suggest that GbE has the neuroprotective effects of ischemic brain damage.
\end{abstract}

Keywords: NGF; OGD; PC12 Cells; Ginkgo Biloba; Neuroprotective Effects

\section{Introduction}

Ischemic stroke occurs when the blood supply to the brain is obstructed. Accumulating evidence suggests that the cell death observed during the first few hours of cerebellar ischemia is a result of apoptosis as opposed to necrosis, which is considered the predominant form of cerebellar damage generated by ischemia. Moreover, effective methods of preventing and controlling ischemic cerebrovascular disease have been a topic of great interest.

Ginkgo biloba extract (GbE) is obtained from green leaves of the Ginkgo biloba tree according to a well-defined procedure [1]. The GbE displays, mainly via its flavonoid constituents, free radical scavenging and antioxidant actions that are probably associated with its protective actions in animal models of hypoxia and ischaemia [2]. Earlier studies have described its neuroprotetive and neurotrophic activities in the hippocampal formation. GbE is already recognized as a polyvalent therapeutic agent in the treatment of disturbances of multifactorial origin including cerebral insufficiency and mild cognitive impairments in elderly patients [3]. Several clinical

${ }^{*}$ Corresponding author. studies support the potential usefulness of $\mathrm{GbE}$ in $\mathrm{AD}$ and in vascular dementia.

In this study, the oxygen-glucose deprivation of PC12 cells was used to establish a cerebral hypoxia-ischemia model to investigate the mechanism of GbE neuroprotection. In the following research, we measure the induction of superoxide dismutase (SOD) in an attempt to elucidate possible mechanisms that underlie GbE-mediated protection against OGD in PC12 cells.

\section{Materials and Methods}

\subsection{Cell Culture and Differentiation by NGF}

PC12 cells were purchased from the Cell Bank of the Chinese Academy of Sciences. The cell line was maintained in DMEM medium supplemented with $10 \%(\mathrm{v} / \mathrm{v})$ fetal bovine serum and 5\% horse serum (FBS, GIBCO), $100 \mathrm{IU} / \mathrm{ml}$ streptomycin, $100 \mathrm{IU} / \mathrm{ml}$ penicillin, $\mathrm{pH}$ 7.0, and detached with $0.25 \%$ trypsin (Sigma, USA). PC12 cells were grown at $37^{\circ} \mathrm{C}$ in $5 \% \mathrm{CO}_{2}$. Cells were grown in $5 \%$ horse serum containing media on collagen-coated tissue culture dishes before differentiation [5]. After the cells got attached, they were treated with $100 \mathrm{ng} / \mathrm{ml}$ 
nerve growth factor (NGF 2.5S; Promega, Madison, WI) and Cultured with serum-free DMEM for 6 days. Observed and photographed.

\subsection{MAP2 Immunocytochemical Analysis}

The cells were fixed with 4\% paraformaldehyde/PBS and were permeabilized with $0.1 \%$ Triton X-100 in PBS for $10 \mathrm{~min}$. The cells were then incubated in 5\% goat serum/PBS for $1 \mathrm{~h}$ at room temperature. Cells were washed again then incubated at $4{ }^{\circ} \mathrm{C}$ overnight in the presence of anti-MAP2 (1:1000 dilution, Santa SC-20172). After washing twice with PBS, the cells were incubated with fluorescently labeled secondary Cy3-goat anti-rabbit (Santa) for 1 hour at room temperature [5]. The results were observed by a fluorescence microscope equipped with a photomicrograph system.

\subsection{OGD Model of PC12 Cells after NGF Treatment}

PC12 cells were treated with NGF for 6 days. Cells were then washed 3 times with DMEM, and the cells were cultured with DMEM in the presence of no sugar and 1 $\mathrm{mmol} / \mathrm{l} \mathrm{Na}_{2} \mathrm{~S}_{2} \mathrm{O}_{4}$ in hypoxic conditions $\left(37^{\circ} \mathrm{C}, 5 \% \mathrm{CO}_{2}\right.$ and $95 \% \mathrm{~N}_{2}$ ) for $3 \mathrm{~h}, 6 \mathrm{~h}, 9 \mathrm{~h}, 12 \mathrm{~h}, 16 \mathrm{~h}$, or $24 \mathrm{~h}$.

\subsection{Cell Viability Assay}

The MTT method was used to assess the cytotoxic effects of GbE. The cells were grown to a density of $5 \times$ $10^{4}$ cells/well and were then treated with $10 \mathrm{ng} / \mathrm{ml}, 20$ $\mathrm{ng} / \mathrm{ml}, 30 \mathrm{ng} / \mathrm{ml}, 50 \mathrm{ng} / \mathrm{ml}$ and $100 \mathrm{ng} / \mathrm{ml} \mathrm{GbE} \mathrm{in} \mathrm{a}$ 96-well plate for $24 \mathrm{~h}$. At the end of the treatment, the GbE -containing medium was carefully removed and the cells were treated with OGD for $16 \mathrm{~h}$. The culture medium was removed and $200 \mu \mathrm{l}$ medium containing $20 \mu \mathrm{l}$ MTT (5 mg/ml in PBS) (St. Louis, MO, USA) was added to each well. After $4 \mathrm{~h}$ of incubation at $37^{\circ} \mathrm{C}$, the medium was removed and $100 \mu \mathrm{l}$ DMSO was added to each well. The optical absorbance (A) of each well was read at 490 $\mathrm{nm}$. The percentage of viable cells was calculated as follows: (A of experimental group/A of control group) $\times$ $100 \%$.

\subsection{Hoechst 33258/PI Staining}

The cells were washed three times with DMEM and were incubated in DMEM containing $50 \mathrm{ng} / \mathrm{ml} \mathrm{GbE}$ for $24 \mathrm{~h}$. The cells were washed three times with DMEM and were incubated for $16 \mathrm{~h}$ in DMEM containing $1 \mathrm{mmol} / \mathrm{l}$ $\mathrm{NaS}_{2} \mathrm{O}_{4}$ under hypoxic conditions $\left(37^{\circ} \mathrm{C}, 5 \% \mathrm{CO}_{2}\right.$ and $95 \% \mathrm{~N}_{2}$ ) in the absence of sugar [5] The cells were stained with PI $(10 \mu \mathrm{g} / \mathrm{ml})$ and Hoechst $33258(10 \mu \mathrm{g} / \mathrm{ml}$, Sigma, USA) and then fixed by $4 \%$ paraformaldehyde. For each cover slide, $1000 \sim 1500$ cells were examined under a fluorescence microscope (Olympus BX51, Japan) and photographed with a digital camera (Olympus, Japan). The results were expressed as the percentages of apoptotic cells and necrotic cells, respectively.

\subsection{Western Blotting Analysis}

After treatment with GbE and OGD for $16 \mathrm{~h}$, the cells were washed twice using cold PBS and $1 \times 10^{6}$ cells

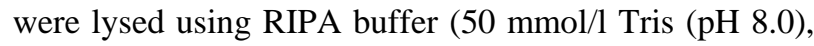
$150 \mathrm{mmol} / \mathrm{l} \mathrm{NaCl}, 0.1 \%$ SDS, $1 \% \mathrm{NP} 40$ and $0.5 \%$ sodium deoxycholate) containing protease inhibitors (1\% cocktail and $1 \mathrm{mmol} / \mathrm{l} \mathrm{PMSF}$ ). Total proteins were separated using $15 \%$ SDS-PAGE and were transferred to a PVDF membrane. The membrane was blocked using Tris-buffered saline with $0.1 \%$ Tween 20 (pH 7.6, TBST) for $1 \mathrm{~h}$ at room temperature and was incubated with the primary antibody solution $(1: 1000)$ at $4^{\circ} \mathrm{C}$ overnight. After two washes in TBST, the membrane was incubated with the HRP-labeled secondary antibody (Santa SC2073) for $1 \mathrm{~h}$ at room temperature and was washed three times with TBST. The final detection was performed using enhanced chemiluminescence (ECL) western blotting reagents (Amersham Biosciences, Piscataway, NJ) and the membrane was exposed to Lumi-Film Chemiluminescent Detection Film (Roche). Loading differences were normalized using a monoclonal $\beta$-actin antibody. The antibodies used in the study included SOD (Santa SC-18503) and $ß$-actin (Santa SC-2021).

\subsection{Statistical Analysis}

SPSS software was used for statistical analyses, and values are presented as means \pm SD. An ANOVA was used to compare the mean values. $\mathrm{P}$ values less than 0.05 were considered to indicate statistically significant differences.

\section{Results}

\subsection{Morphological Changes of PC12 Cells}

The results show that treatment with NGF (100 ng/ml) stimulates neuron-like differentiation of PC12 cells as seen under the microscope. PC12 cells changed into neurons after 1 day of NGF treatment and later formed synapses. Synapses extended up the length of the cell after 3 days of treatment. The synaptic length increased 6 -to 8 -fold after 6 days of treatment. Bars $=20$ um, Invert microscope, Olympus IX71, Japan (×200) (Figure 1).

\subsection{Immunofluorescence Analysis}

The results showed that PC12 cells cultured with NGF for 6 days showed characteristic MAP2 immunofluorescence staining (Figure 2). Application plus pro 6.0 software to add image fusion after confirm purple fluores- 


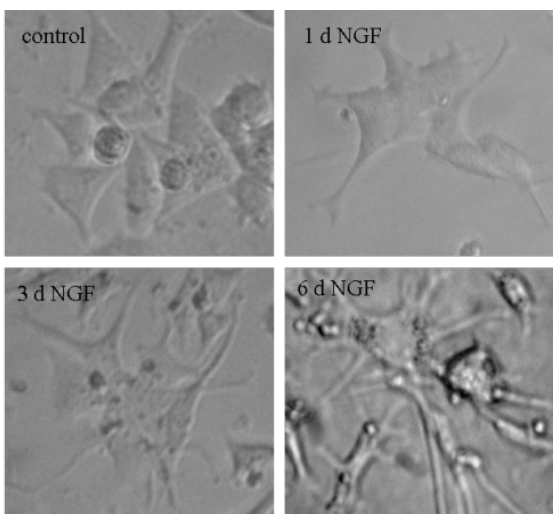

Figure 1. The morphological changes of PC12 cells $(\times 200)$. PC12 cells were pretreated with $100 \mathrm{ng} / \mathrm{ml}$ NGF for $1,2,3$, 4 , or $6 \mathrm{~d}$. The differentiated cells were photographed under a phase contrast microscope.

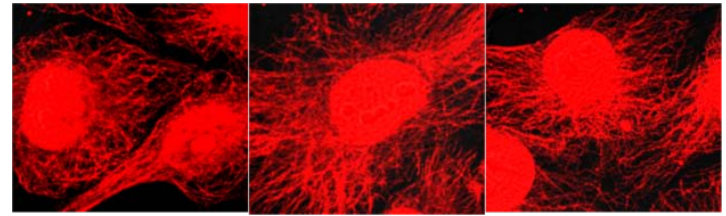

Figure 2. Morphological changes captured with fluorescence microscopy following immunofluorescence staining $(\times 400)$.

cent were for PC12 cells transformation of neurons appearance cell. MAP2 immunofluorescence stain was strong positive expression. PBS control was negative fluorescence.

\subsection{Effects of GbE on Cell Proliferation}

The cytotoxicity of OGD for $16 \mathrm{~h}$ and GbE (Yabao Shanxi China) plus OGD for 16 h treatments were determined by examining their effects on the proliferation of PC12 cells. PC12 cells were treated with $10 \mathrm{ng} / \mathrm{ml}, 20$ $\mathrm{ng} / \mathrm{ml}, 30 \mathrm{ng} / \mathrm{ml}, 50 \mathrm{ng} / \mathrm{ml}$ and $100 \mathrm{ng} / \mathrm{ml} \mathrm{GbE}$ for $24 \mathrm{~h}$ before OGD for $16 \mathrm{~h}$ (Figure 3). MTT assays showed that treatment with OGD for 16 h effectively inhibited the growth of PC12 cells by $19.44 \%$. Compared to the OGD for 16 h-treated group, the Ginkgo biloba plus OGD for 16 h-treated group inhibited the growth of PC12 cells by $17.82 \%, 13.31 \%, 10.36 \%, 4.29 \%$ and $3.92 \%$, in dose-dependent manner, and the survival rates were higher than in the OGD for 16 h-treated group. Because there was no significant difference $(P>0.05)$ between the survival rates of the $50 \mathrm{ng} / \mathrm{ml}$ and $100 \mathrm{ng} / \mathrm{ml}$ GbE-treated cells, $50 \mathrm{ng} / \mathrm{ml}$ GbE was used in all subsequent experiments.

\subsection{Hoechst 33258/PI Staining}

The representative microphotographs show the PC12 cells as detected by PI staining after OGD-reperfusion

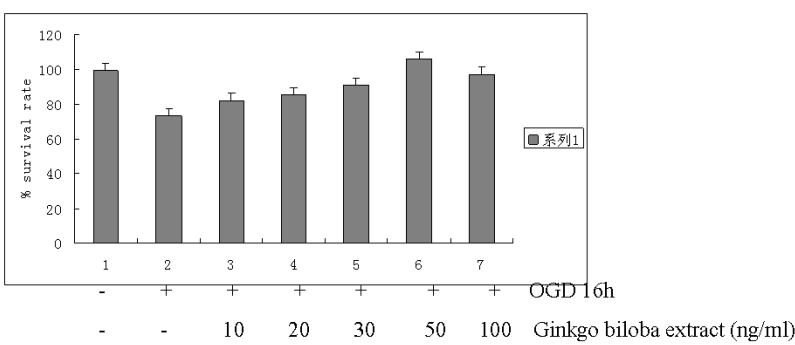

Figure 3. MTT assay showing the growth inhibition of PC12 cells treated with Ginkgo biloba for $24 \mathrm{~h}$ plus OGD for $16 \mathrm{~h}$. The cells were grown to a density of $5 \times 10^{4}$ cells per well in a 96-well plate for $24 \mathrm{~h}$. The results show the growth of PC12 cells following incubation in 96-well plates for $24 \mathrm{~h}$ with $10 \mathrm{ng} / \mathrm{ml}, 20 \mathrm{ng} / \mathrm{ml}, 30 \mathrm{ng} / \mathrm{ml}, 50 \mathrm{ng} / \mathrm{ml}$ and $100 \mathrm{ng} / \mathrm{ml}$ Ginkgo biloba plus OGD for $16 \mathrm{~h}$, compared with OGD for 16 h. "denotes a significant difference from control, $P<0.05$; ** denotes a significant difference from OGD for $16 \mathrm{~h}, \mathrm{P}<$ 0.05; denotes a significant difference from $50 \mathrm{ng} / \mathrm{ml}$ Ginkgo biloba plus OGD for $16 \mathrm{~h}, \mathrm{P}<0.05$. The data represent the means \pm SD obtained from three separate experiments that were performed in triplicate.

induced injury; The representative microphotographs show the apoptotic cells as detected by Hoechst 33258 staining after OGD-reperfusion induced. GbE effectively increases the survival rate of PC12 cells and relieves OGD damage. The summarized data show percentage changes in the numbers of normal and apoptotic cells. Data are expressed as mean \pm SD; $n=4$ wells for each group; ${ }^{*} \mathrm{P}<0.05$ and ${ }^{* *} \mathrm{P}<0.01$, compared to control and other group (Figure 4).

\subsection{Effects of Ginkgo Biloba on SOD}

SOD plays a protective role in ischemia following its activation. To investigate the neuroprotective mechanisms of GbE, the expression of SOD were examined using western blots (Figure 5). Compared with the controls, SOD expression levels in PC12 cells increased in the OGD for the 16 h-treated group. Compared with this group, the expression levels of OGD increased in the groups treated with GbE for 24 h combined with OGD for $16 \mathrm{~h}$. In this group, as the concentration of Ginkgo biloba increased, the expression levels of OGD increased in a dose-dependent manner. GbE may mediate the neuroprotective effect by OGD.

\section{Discussion}

Rat adrenal pheochromocytomas have been made into PC12 cell lines. PC12 rat pheochromocytoma cells are one of the most widely used cell culture systems for studying neuronal differentiation [4]. In this study, we used physical and chemical methods to establish OGD conditions, and we used sugar-free culture medium and $\mathrm{NaS}_{2} \mathrm{O}_{4}$ to establish a liquid environment lacking oxygen 


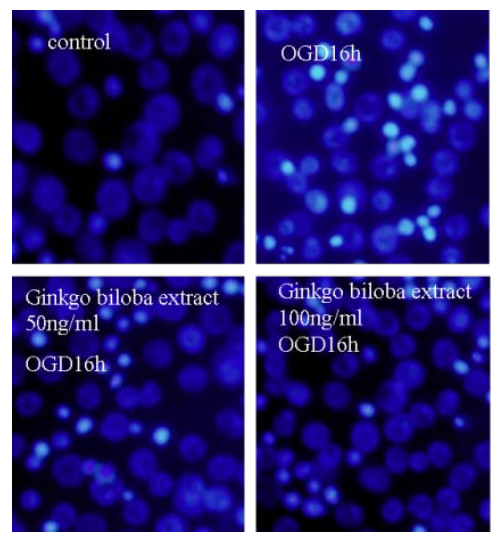

Figure 4. The cell death was analyzed by double fluorescent staining with Hoechst 33258 and propidium iodide (PI).

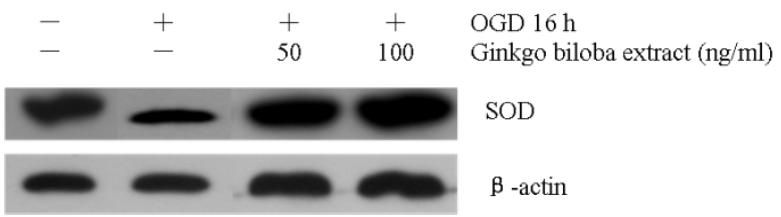

Figure 5. PC12 cells were treated with OGD for $16 \mathrm{~h}$ or different concentrations of Ginkgo biloba for 24 h combined with OGD for $16 \mathrm{~h}$. OGD expression levels were determined using western blots. The results shown are representative of three independent experiments. NIH imaging indicated that the protein signal densities increased in the groups treated with Ginkgo biloba combined with OGD for 6 h compared with OGD for 6 h-treated groups.

and sugar [5]. The circulation of oxygen and glucose is necessary to maintain neurons' normal physiology function and survival. During the ischemic damage process, neurons' blood supply is disrupted. OGD is a model of oxygen and glucose shortage. We used the OGD on neurons to simulate the ischemic brain damage process that occurs in the body. We used NGF combined with OGD to set up an ischemia tolerance model. Our study shows that PC12 cells treated with NGF form cells are neuron-like in appearance. These results may help to establish NGF treatment followed by OGD as an in vitro model of acute ischemic brain damage. The model provides a new tool for the identification of pathways that are involved in cerebral ischemia. This cerebral ischemic model is one example of the cell's broader general-stress response. Therefore, the present model could be applied to the study of mechanisms that are involved in tolerance to other stressful stimuli. Cell-based assays with highthroughput capacity can be used as direct screens and models to explore molecular mechanisms that are involved in cellular function and pathology.

In the present study, we examined MAP2 expression by immunoblotting. MAP2 is a neuron specific protein. Microtubule stabilizing is critical for neurite outgrowth and dendrite development. So MAP2 is widely used as a marker and plays a critical role in neurite outgrowth. It is a helpful diagnostic and prognostic feature in various neurological disorders. We found that MAP2 is expressed in PC12 cells that had been exposed to NGF. Tolerance to ischemia and hypoxia can be modeled in vitro and has been described in cultured PC12 cells.

An OGD-damage model is one of the more commonly used models for the study of cerebral ischemia. The principle of the OGD model is that $\mathrm{Na}_{2} \mathrm{~S}_{2} \mathrm{O}_{4}$ quickly clears the oxygen in the culture matrix. In this study, oxygen and glucose deprivation are applied to PC12 cells and the results show that the OGD for 16 h-treated group effectively inhibits the growth of PC12 cells, indicating that the cell model causes cell damage. When compared with the OGD for 16 h-treated group, the GbE plus OGD for 16 h-treated groups effectively increased the survival rate of PC12 cells (Figures 3 and 4). Therefore, ginkgo biloba has a protective effect on OGD-induced cell injury.

Many studies indicate that oxidative stress plays a key role in ischemic cerebrovascular disease. SOD plays a vital role in the body's oxidant and antioxidant balance by removing superoxide anion radicals and protecting cells from damage. SOD is involved in oxidative damage. The results show GbE increases SOD activity, and this may be the mechanism by which GbE promotes the neuroprotective effect (Figures 4 and 5). In conclusion, our results demonstrate that GbE protects PC12 cells in an OGD-deprivation model though reducing apoptosis rate.

\section{REFERENCES}

[1] K. Drieu, "Preparation and Definition of Ginkgo Biloba Extract,” Presse Medicale, Vol. 15, 1986, pp. 1455-1457.

[2] L. Marcocci and J. J. Maguire, "The Nitric Oxide-Scavenging Properties of Ginkgo Biloba Extract EGb 761," Biochemical and Biophysical Research Communications, Vol. 201, 1994, pp. 748-755. http://dx.doi.org/10.1006/bbrc.1994.1764

[3] H. Oberpichler and T. Beck, "Effects of Ginkgo Biloba Constituents Related to Protection against Brain Damage Caused by Hypoxia Pharmacol,” Research Communications, Vol. 20, 1988, pp. 349-368.

[4] M. E. Szabo and M. T. Droy-Lefaix, "Direct Measurement of Free Radicals in Ischemic/Reperfused Diabetic Rat Retina," Clinical Neuroscience, Vol. 4, 1997, pp. 24-245.

[5] C. L. Mei and J. T. He, "Nerve Growth Factor (NGF) Combined with Oxygen Glucose Deprivation (OGD) Induces Neural Ischemia Tolerance in PC12 Cells,” AJBR, Vol. 5, No. 10, 2011, pp. 315-320. 